\title{
PESONA FORM DRIVEN DARI TIPOGRAFI PADA KEMASAN MAKANAN DAN MINUMAN
}

\author{
Julianto \\ Jurusan Desain Komunikasi Visual, Fakultas Komunikasi dan Multimedia, \\ Bina Nusantara University, Jln. K.H. Syahdan No. 9, Palmerah, Jakarta 11480
}

\begin{abstract}
Letters or widely known in the designer community design as typography, is the most essential design element, because it has a double function, as both the language of verbal and also visual language. Its presence in the design world often dominates the portion of the design. It is also often evident in many information media, and capable of persuading its audience through the enchanting beauty (form driven), both types of letter itself and its well-ordered structure, designed by a designer. This also occur in food and beverage packaging, which when people make very careful decisions, since it involves preferences or consumption of their own choice, is an added value if their favorite food/drink is packed with a cool typography design.
\end{abstract}

Keywords: Typography, composition, emphasis

\begin{abstract}
ABSTRAK
Huruf atau banyak dikenal dimasyarakat desain dengan tipografi, adalah elemen desain yang paling esensial, karena fungsinya yang ganda, sebagai bahasa verbal maupun bahasa visual. Kehadirannya di tatanan desain sangatlah mengambil porsi yang seringkali mendominasi. Hal ini terbukti kerap terjadi pada banyak media informasi, dan sanggup meyakinkan pemirsanya melalui pesona keindahan (form driven), baik jenis huruf itu sendiri maupun stuktur yang tertata baik, yang merupakan hasil rancangan seorang desainer. Ini juga terjadi pada kemasan makanan dan minuman, yang ketika orang mengambil keputusan sudah dalam pertimbangan masak-masak, karena menyangkut kesukaan atau konsumsi pilihan mereka sendiri, adalah suatu nilai tambah jika makanan/minuman kesukaan mereka dikemas dengan desain huruf yang keren.
\end{abstract}

Kata kunci: Tipografi, komposisi, penekanan 


\section{PENDAHULUAN}

Form driven adalah ekspresi visual, visual emotion, abstraksi visual.

\section{Sekilas Sejarah Huruf}

Huruf atau tipografi adalah sesuatu yang hadir setiap saat mengelilingi kita, di pakaian kita, di rumah, di taman, di gedung. di kendaraan, dimanapun kita berada akan bertemu dengan yang namanya huruf. Huruf hadir sebagai gagasan untuk menulis yang ditandai oleh bentuk visual tertentu pengganti komunikasi lewat oral. Perkembangan jenis huruf sekarang dikreasikan berangkat dari desain huruf awal sejarah budaya tulis menulis. mulai masa kejayaan bangsa Mesopotamia, di daerah mediterania 4000 tahun SM, berupa batu bertulis, dicukil (lihat Gambar 1). Pengembanganya sampai dengan abad ke 6 dan 7 SM.
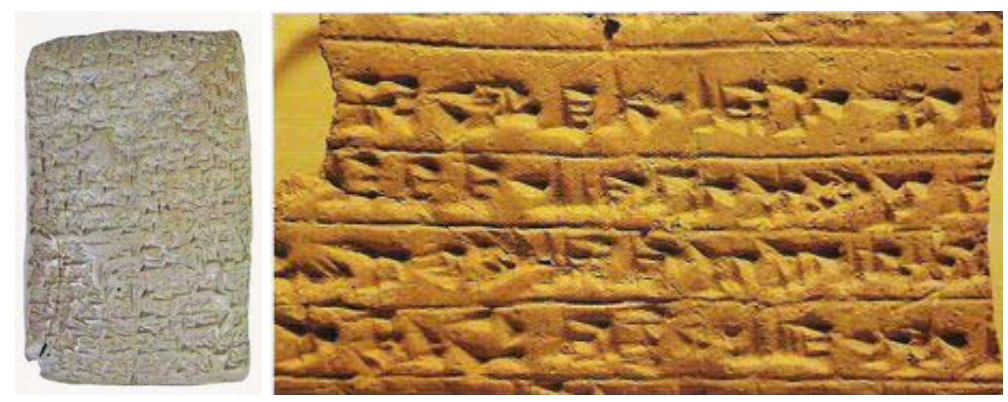

Gambar 1Cuneiform Awal (Kiri) dan Cuneiform Tablet (Kanan) Lebih Detail

Sampai saat kini kita mengenal 4 akar bahasa di dunia, yaitu Latin, Arab, Cina dan Boustrophedon, yang masing masing memiliki arah baca yang berbeda : Latin, dari kiri ke kanan ; Arab dari kanan ke kiri ; China dari atas ke bawah ; Boustrophedon dari atas ke abwah dengan tidak terputus seperti ular (lihat Gambar 2).

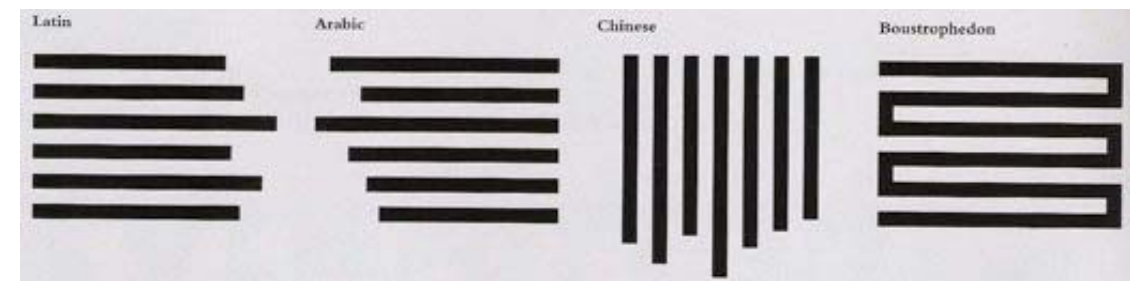

Gambar 2 Akar Bahasa di Dunia

Tulisan juga dibedakan dalam bentuk yang hampir sama dengan istilah yang berbeda, yaitu: (1) Phonogram, yaitu simbol tulisan, huruf, karakter atau tanda lain yang merepresentasikan sebuah suara, syllable, morpheme atau kata; (2) Ideogram, yaitu elemen grafis yang merepresentasikan sebuah gagasan atau sebuah konsep (contoh pada Gambar 4); (3) Icon / Ikon, yaitu elemen grafis yang merepresentasikan sebuah objek, orang atau sesuatu; (4) Symbol / Simbol, yaitu elemen grafis yang mengkomunikasikan tidak sekedar bentuk nyatanya tetapi ada makna tersirat dibalik bentuk tersebut(simbolis-konotatif); (5) Pictogram, yaitu sebuah elemen grafis yang menjelaskan gestur atau seri gerakan yang menjadi visual referensi atau arahan visual (contoh pada Gambar 3). 


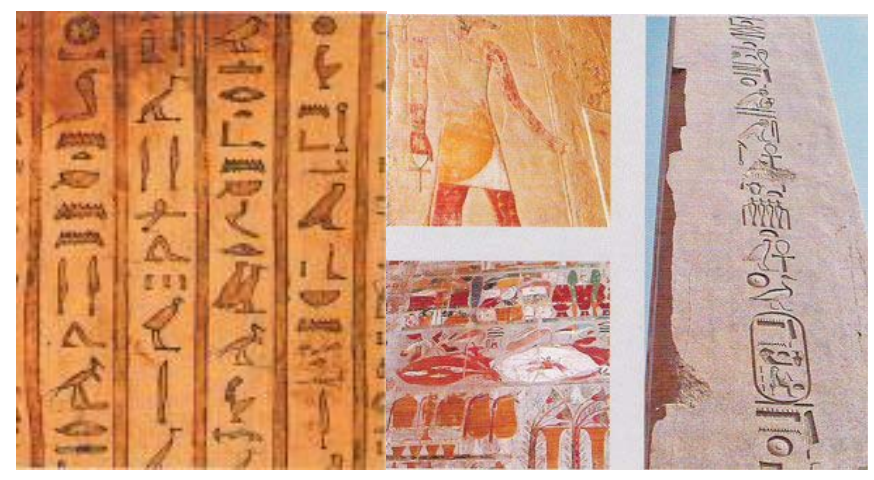

Gambar 3 Hieroglyphs Termasuk Jenis Pictogrammatic

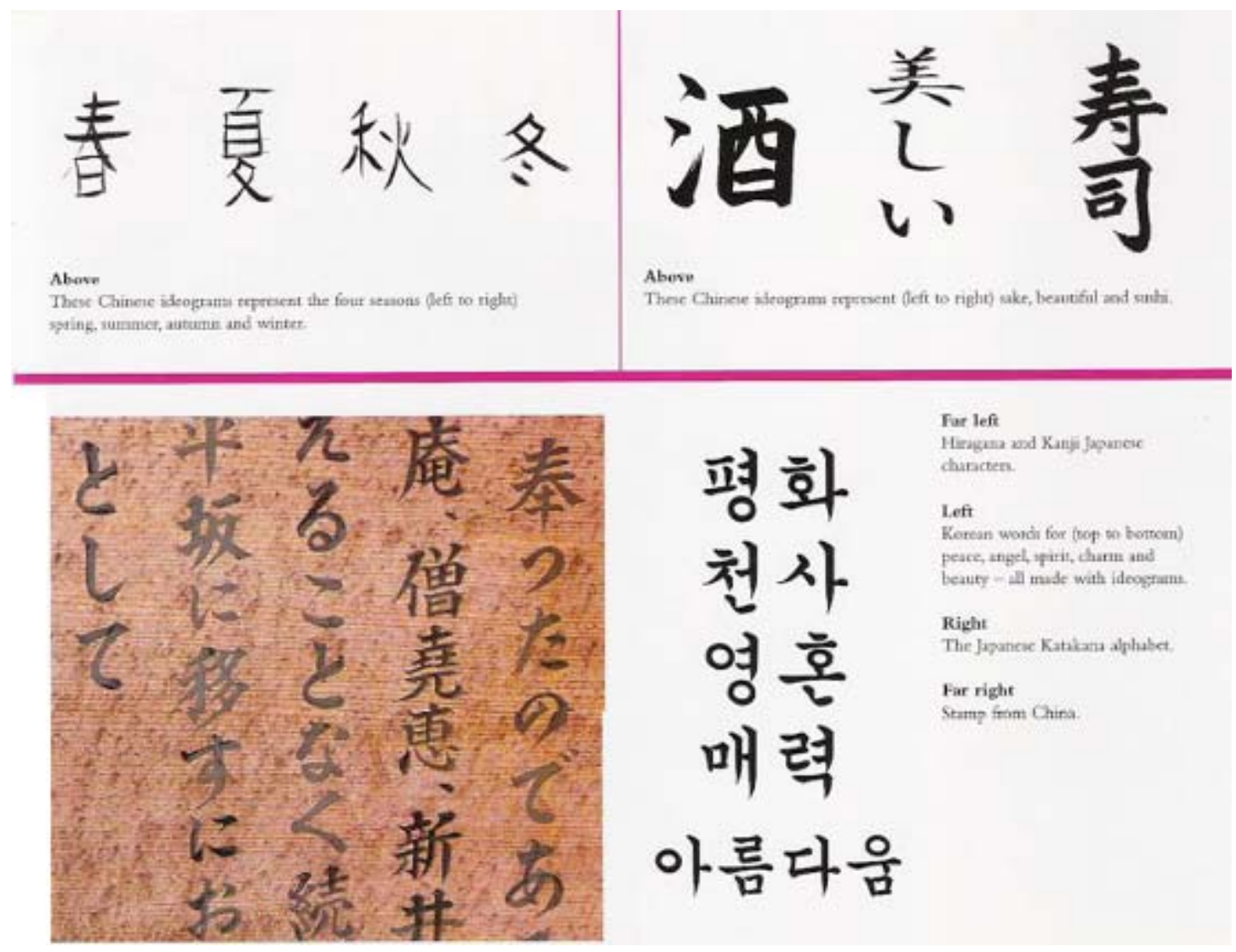

Gambar 4 Ideogram Cina yang Merepresentasikan Empat Musim (Kiri Atas) dan Ideogram Jepang Merepresentasikan Sake, Indah, dan Sushi (Kanan Atas)

Bahasa ideogrammatic (lihat Gambar 4) menggunakan karakter dan symbol untuk menyatakan sebuah gagasan atau konsep tanpa harus mengekspresikan pengucapan dari sebuah kata atau kata-kata. Penting untuk di perhatikan empat poin ini, dalam hubungannya dengan pengucapan, penulisan, pemenggalan, dan suara yang keluar. berguna pada waktu penerapan berkomunikasi (Gambar 5). 


\author{
Phoneme \\ A phoneme describes \\ a speech sound or sign \\ element - the basic \\ unit that distinguishes \\ between different wotds. \\ For example, the phonemes \\ 'o' and ' $x$ ' come together \\ to make 'ox'. \\ DISCREDITED

\begin{abstract}
Morpheme
A morpheme is a distinctive group of phonemes that form the smallest language unit that has a semantic interpretation. $A$ word can be broken into a series of morphemes, with each baving a distinct meaning, The word 'discredited' has three morphemes; 'dis',
\end{abstract} \\ 'credic' and 'ed'.
}

\section{DIS CREDIT ED}

Syllable

A syllable is a unit of spoken language consisting of a single, uninterrupted sound. This may be formed by a vowel, diphthong, a syllabic consonant alone, or by any of these sounds accompanied by one or more consonants. The word "discredited" has four syllables.
Letter

A letter is a mark or glyph (symbol) used in an alphabetic writing system to indicate a sound.

$\underline{\mathrm{D}} \underline{1} \underline{\mathrm{S}} \underline{\mathrm{R}} \underline{\mathrm{E}} \underline{\mathrm{D}} \underline{\mathrm{T}} \underline{\mathrm{E}} \underline{\mathrm{D}}$

Gambar 5 Penulisan, Pemenggalan Suara

Banyak perubahan besar terjadi ketika mesin cetak beroperasi dengan menggunakan susunan huruf(huruf yang disusun - movable type, tahun 1436, yang dimotori oleh Johannes Gutenberg orang Jerman itu (1400-1468) yang keudian kita kenal disini dengan LetterPress. Berawal dari sini terus perubahan demi perubahan dilakukan, jenis huruf terus bertambah, tokoh-tokoh desainer bermunculan, style/gaya menjadi tanda atas jaman: Revolusi industri tahun 1800, disusul kemunculan Pantographic punchcutter, 1885, American Typefounder ATF, 1892, Commercial art, Monotype character caster, 1893, gerakan Art and Craft melahirkan nama-nama Reunie Mackintosh, Otto Eckmann, Franklin Gothic dengan karyanya yang terkenal Copperplate Gothic. Di era Modernism, 1910, De Stijl, 1917, Constructivism, 1918, The Bauhaus, 1919, hingga POP art 1960an, tibalah di era 2000an. Perkembangan tipografi dari masa ke masa ditampilkan pada Gambar 6.

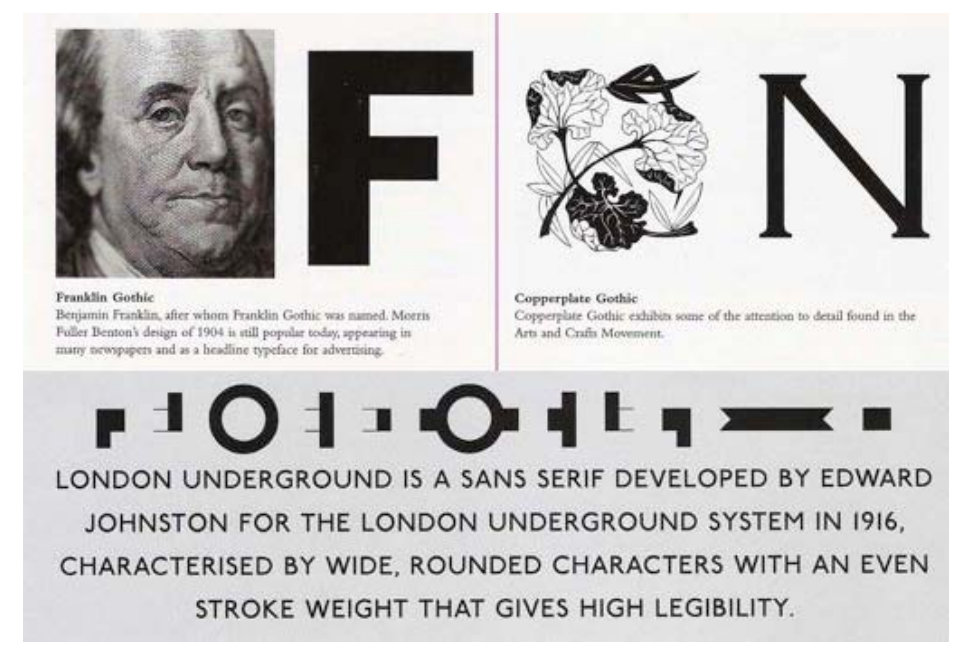

Johnston Underground, 1916

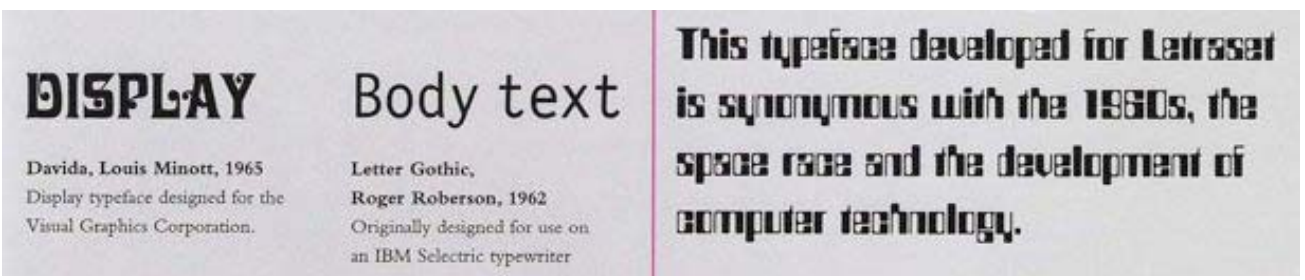

Davida, Louis Minott, 1965 / Letter Gothic, Roger Roberson, 1962 


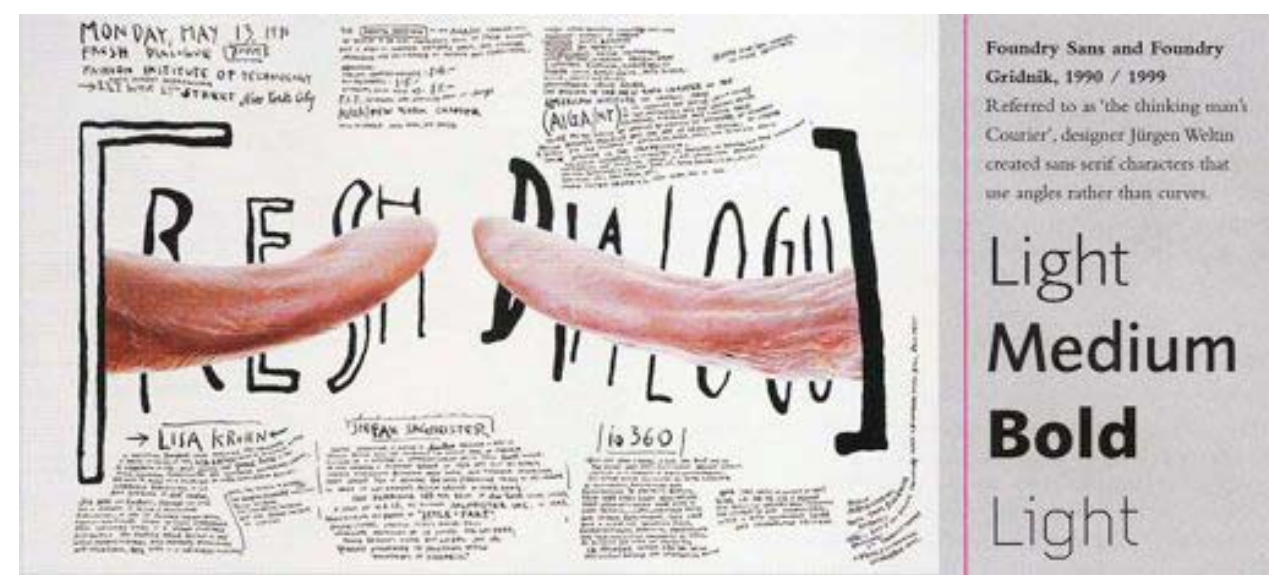

Fresh Dialogue oleh Stefan Sagmeister, 1996
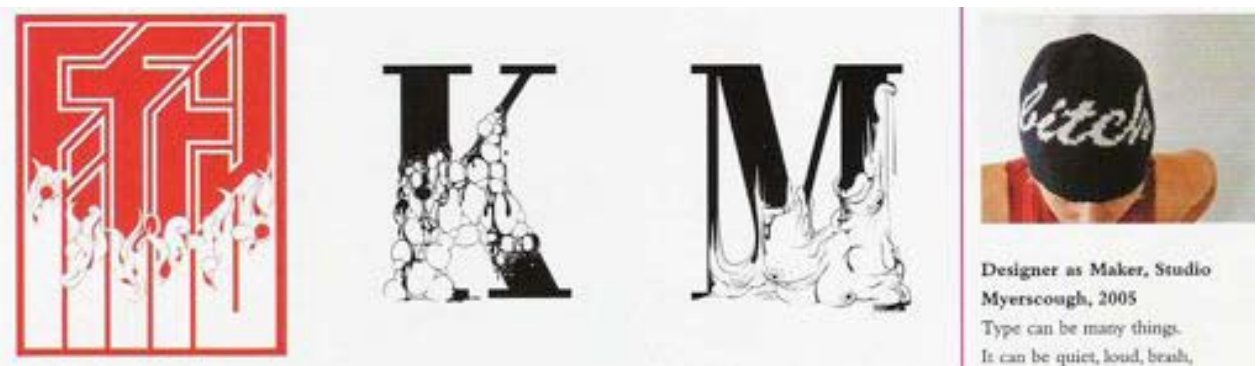

Diesel Fifty book oleh Visava Artworks, 2006

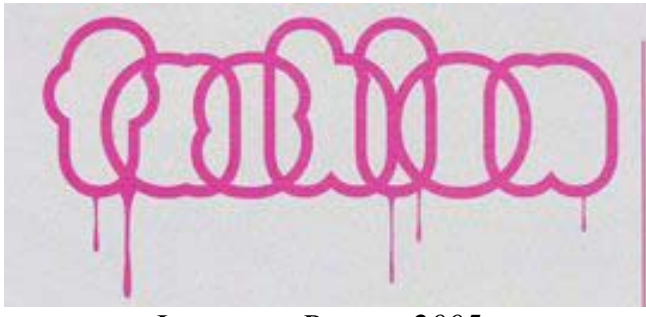

Logotype, Parent, 2005

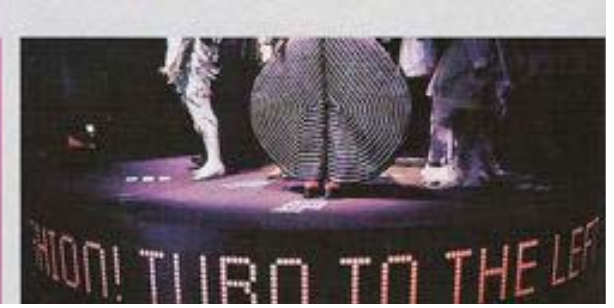

Rock Style, Studio Myerscough, 2005

Gambar 6 Perkembangan Tipografi dari Masa ke Masa

\section{Pengenalan Anatomi, Jenis Huruf dan Keluarganya}

Typefaces dan fonts, dua kata yang sering samar pengertian. Dalam penggunaan biasanya typeface dan fonts hampir sama, tetapi dalam beberapa kasus dengan substansi yang khusus harusnya desainer menetapkan kata yang tepat untuk menjelaskan definisinya, Typeface adalah kumpulan karakter, huruf, nomor, symbol, dan tanda baca yang memiliki kesamaan desain. Font adalah bentuk fisik dari typeface, baik itu mesin tik, mesin stensil, mesin letterpress atau bentuk-bentuk lain yang berhubungan dengan typeface. Felici (2002) menjelaskan perbedaannya : "As a font being a cookie cutter and the typeface the cookies produced"

\section{Typeface Anatomy/ Anatomi Huruf}

Menarik dalam judul ini, huruf disamakan dengan tubuh manusia, sedemikian pentingnya pembagian dari tubuh sebuah huruf, sehingga harus di uraikan begitu lengkap, masing-masing memiliki bentuk dan atribut sendiri yang unik (lihat Gambar 7): 


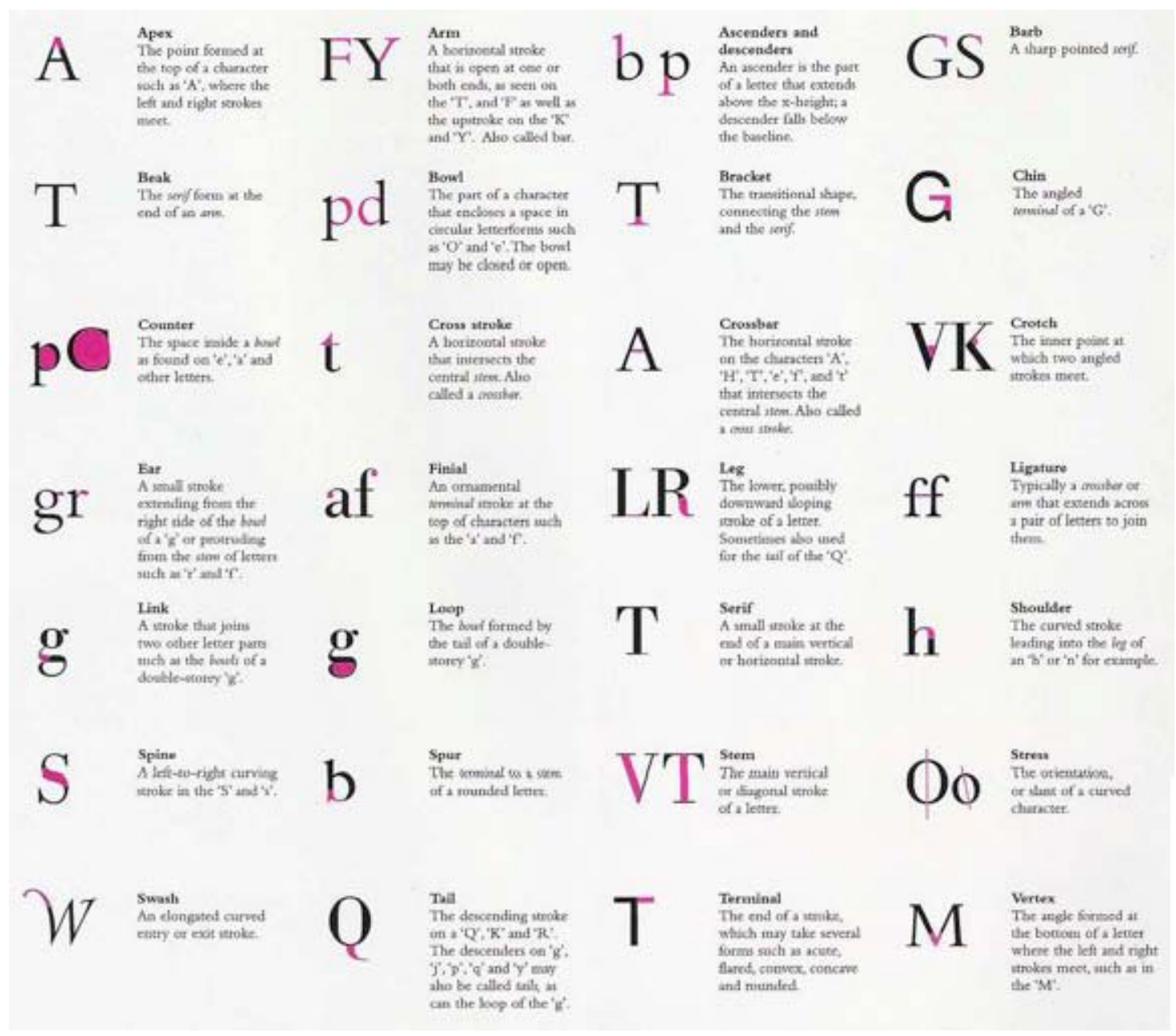

Gambar 7 Anatomi Huruf

Dari mulai kepala, badan, pundak, telinga, kaki, penyanggah, sampai ekor pun disebutkan guna memberi karakter untuk pembeda dengan jenis huruf lain.

Pada penggunaannya dikenal dengan huruf besar (uppercase/ capital/ majuscule) dan huruf kecil (lowercase/ minuscule) dan diatur oleh garis bantu, Baseline grid agar baik dan benar kedudukannya, kemudian ukuran tinggi huruf digunakan satuan point disingkat pt. Bahkan untuk menjaga keseimbangn ideal atau proporsi harmonis mengacu pada hukum the Golden section dengan perbandingan $0+1=1 ; 1+1=2 ; 1+2=3 ; 2+3=5 ; 3+5=8 ; 5+8=13 ; 8+13=21$; begitu seterunya popular dengan sebutan Fibonacci Sequence/series.

\section{Type Family / Keluarga Huruf}

Menyangkut seluruh variasi bentuk tertentu dari satu jenis huruf, diantaranya berbeda bobot, ringan berat, lebar, kurus, miring, semua itu cerminan karakter. Gambar 8 adalah contoh kumpulan keluarga huruf Frutiger. 


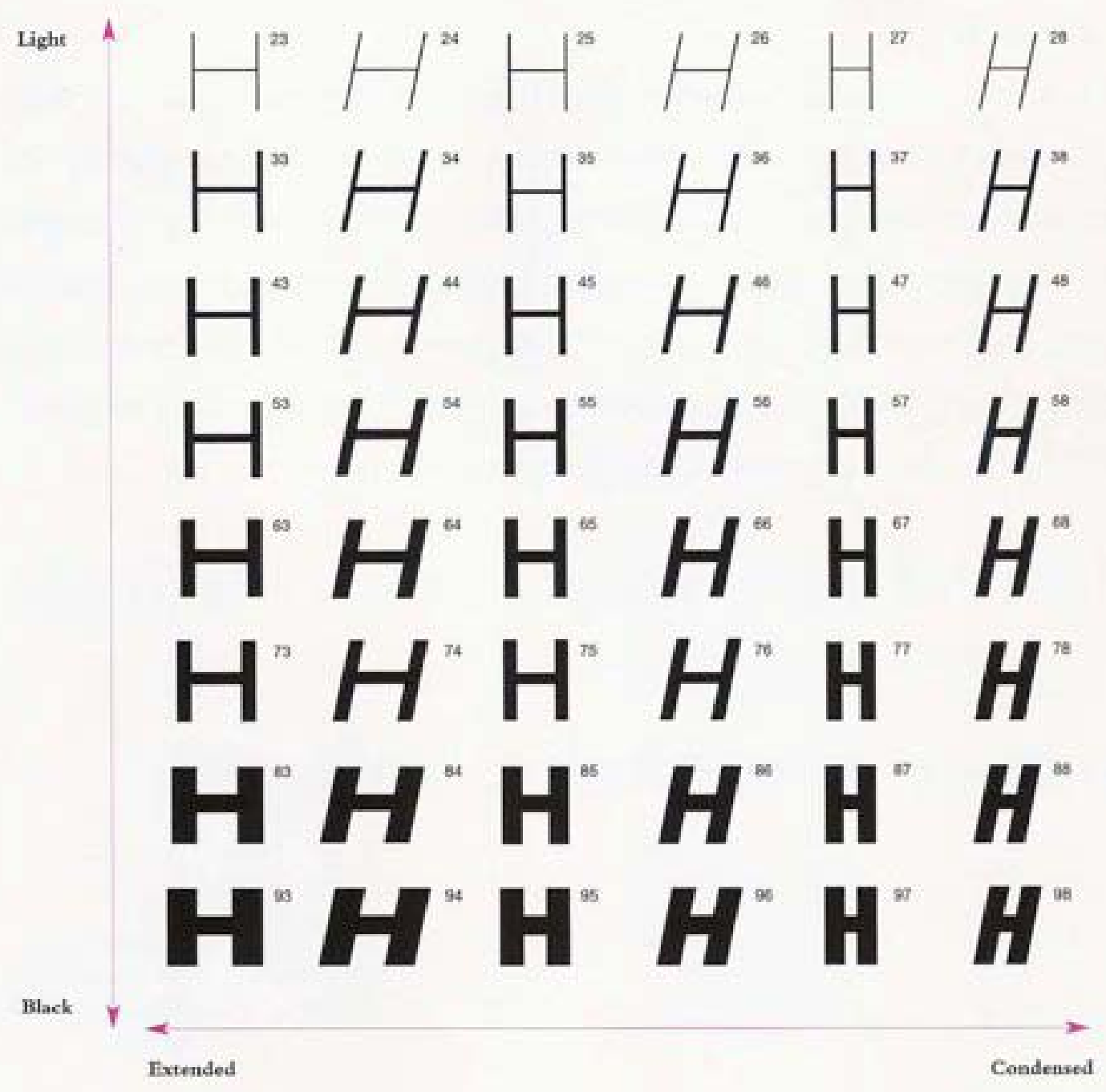

Gambar 8 Contoh Huruf Frutiger

Klasifikasi huruf secara sederhana: Bloct, huruf yang berbasis ornamen, dikenal diabad pertengahan, ditinjau sekarang berkesan antik, untuk teks susah terbaca, lebih tepat untuk judul; Roman, berserif, sangat mudah dibaca, cocok untuk teks / naskah; Gothic, karakternya simple, tidak berkait/serif, disebut sanserif, pada jamannya sukses digunakan untuk bodyteks koran, juga sebagai headline atau displytype; Script, jenis ini di desain sebagi pengganti tulisan tangan, sifatnya menyam bung, beberapa hasilnya mudah dibaca.

\section{Penggunaan di Berbagai Media dengan Teknik Penerapan Bervariasi}

Huruf dapat digunakan sebagai elemen visual untuk mendapatkan dramatisasi desain sebagai alasan kreatif. Namun perlu pertimbangan-pertimbangan yang jeli, Hirarkhi adalah pertimbangan utama dalam mengelola huruf agar lebih terarah dalam urutan komunikasi yang diinginkan. Warna adalah alasan kedua untuk mengoptimalkan kehadirannya lebih kreatif, sehubungan dengan itu teknik cetaklah yang menjadi jawaban yang beralasan: 


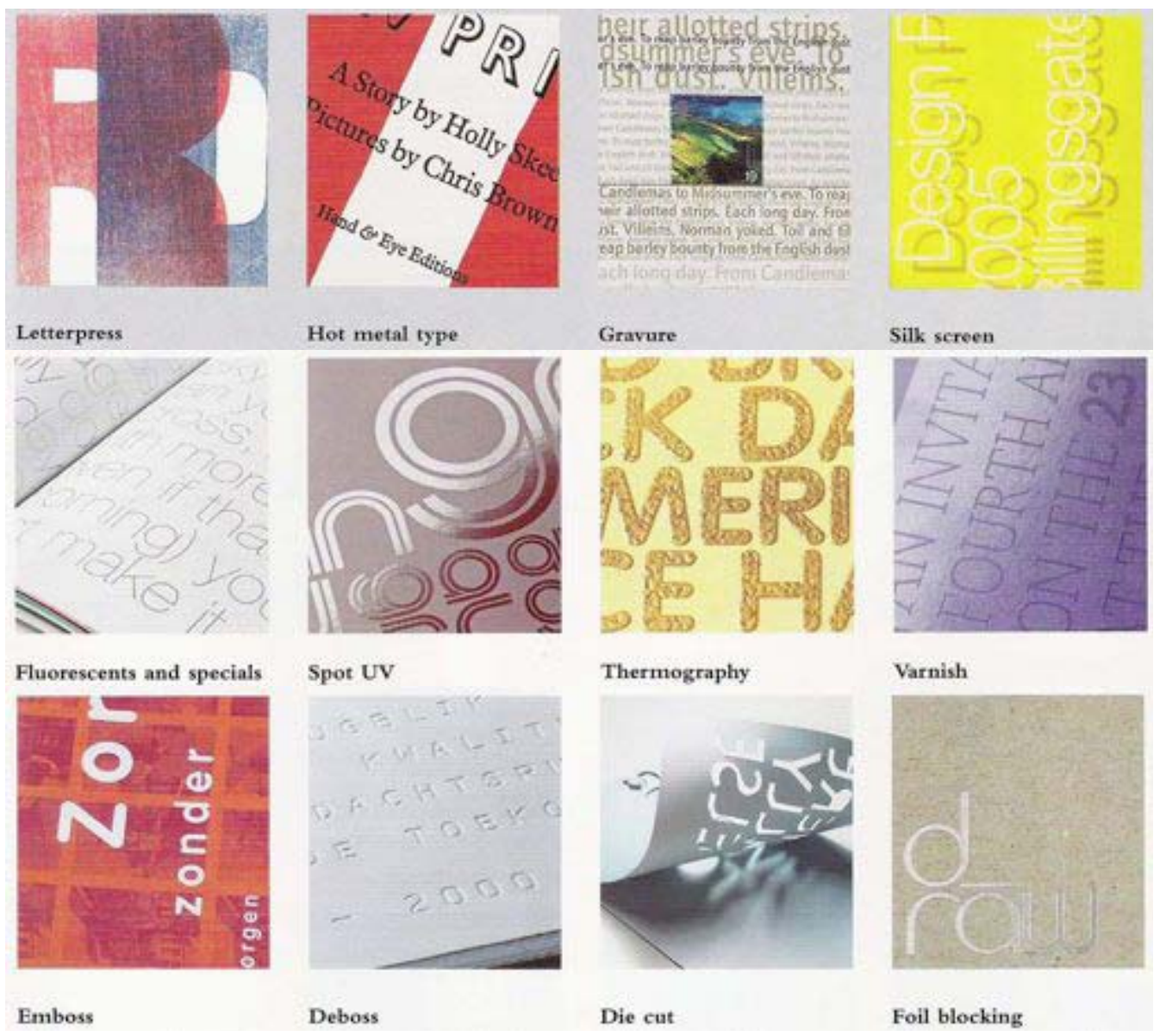

Gambar 9 Contoh-Contoh Teknik Cetak

Gambar-gambar contoh teknik cetak (lihat Gambar 9) sangatlah membantu inspirasi desain dengan menggunakan huruf / tipografi.

Pada penggunaan umum huruf adalah sarana / alat untuk mengkomunikasikan kata-kata, tetapi jangan lupa ia berfungsi sebagai elemen grafis yang mampu berbicara lebih sebagai representasi visual yang sanggup memuat arti dengan maksud tertentu.

\section{Kemasan}

Tidak akan dibahas secara rinci mengenai kemasan, karena hanyalah sebagai media terapan dari huruf atau tipografi yang memegang peran penting disini, kemasan peninjauannya sebatas kedekatannya dengan target sasaran, itupun karena adanya pengaruh / penguasaan huruf disana, tetapi paling tidak kita akan meninjau tiga aspek penting dalam meninjau kemasan :

\section{Aspek fungsi}

- Fungsi praktis, (1) melindungi produk agar didak tercerai berai, dan melindungi dari udara luar supaya tidak terkontaminasi; (2) Kemudahan dalam memegang, memindahkan; dan (3) Distribusi, dengan kemasan berbagai ukuran dan kekuatan (kontainer)

- Fungsi ekonomis, simple, dengan material yang sesuai, menjadi lebih efektif dan akhirnya berujung pada harga, lebih murah, ekonomis. 
- Fungsi promosi, berfungsi sebagai iklan dari produk yang dilindunginya, sesungguhnya aspek ini yang menjadi utama daripada fungsi dasar, melindungi

\section{Aspek Identitas}

- Identitas isi, apakah yang dikemas berbentuk padat, pasta, cair, bubuk, dllsb.

- Identitas diri, apa jenis barang yang dikemas ? makanan, sabun, obat, dllsb.

- Identitas konsumen, apakah pria, wanita, orang sakit, anak-anak, orang tua ?

- Identitas produsen, citra dan kepercayaan masyarakat menjadi tolak ukur.

\section{Aspek Estetika/ Persuasi}

Desain, adalah yang utama di era produk actual / lifestyle, dan Teknologi, yang menciptakan bentuk dan cara penggunaan yang baru dengan material yang baru pula. Sejalan dengan perkembangan waktu, kebutuhanpun bergeser, yang tadinya hanyalah keinginan sekarang sudah menjadi kebutuhan, kemasan tidak hanya diperlukan funsgi dasar/utama, tetapi usur kepuasan lain demi pemenuhan kebutuhan emosi yang meningkat, Franzia (2009) mengatakan "Perkembangan desain kemasan dari fungsi utama kemasan menjasi bergesr, dari yang semula "kemasan melindungi apa yang dijual”, menjadi "kemasan menjual apa yang dilindungi”. Nilai kompetisi menjadi panglima, tuntutan dayatarik diatas segalanya, pesona ada paling depan, maka desain sangatlah mutlak.

Makanan dan minuman adalah adalah kebutuhan mutlak manusia, untuk itu kemasannya harus mencerminkan isi yang ada didalamnya, kebersihan, hieginitas, tangal produksi, batas waktu kadaluarsa, keterangan isi, keterangan cara mengkonsumsi, keterangan nilai nitrisi, halal, keabsahan dari pemerintah yang dinyatakan dengan terteranya no MD...,dari departemen kesehatan, logo produk, diskripsi produk, varian produk, keterangan berat, keterangan jumlah, alamat produksen, hotline service, barcode harga, dan lain-lain, semuanya harus diinformasikan. Disini huruf memegang peranan penting, harus hadir semua dengan tidak menjemukan(sekedar informasi), tetapi tampir dengan persuasi, menggoda penikmatnya.

\section{Prinsip Desain}

Semua referensi diatas menjadi bekal dalam meninjau beberapa desain kemasan dan minuman keren yang memiliki pesona dan daya pikat. Untuk menelaahnya bisa dirujuk dengan menggunakan prinsip Gestalt. Prinsip persepsi visual yang menjadi standard setiap desainer dalam merancang desain komunikasi visual. (1) Closure, (2) Continuance, (3) Similarity, (4) Proximity, (5) Figure and Ground

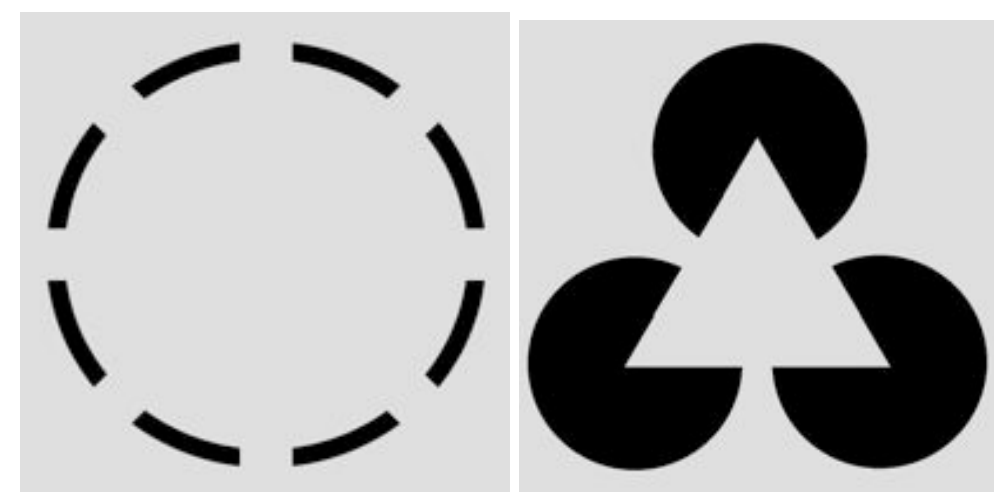



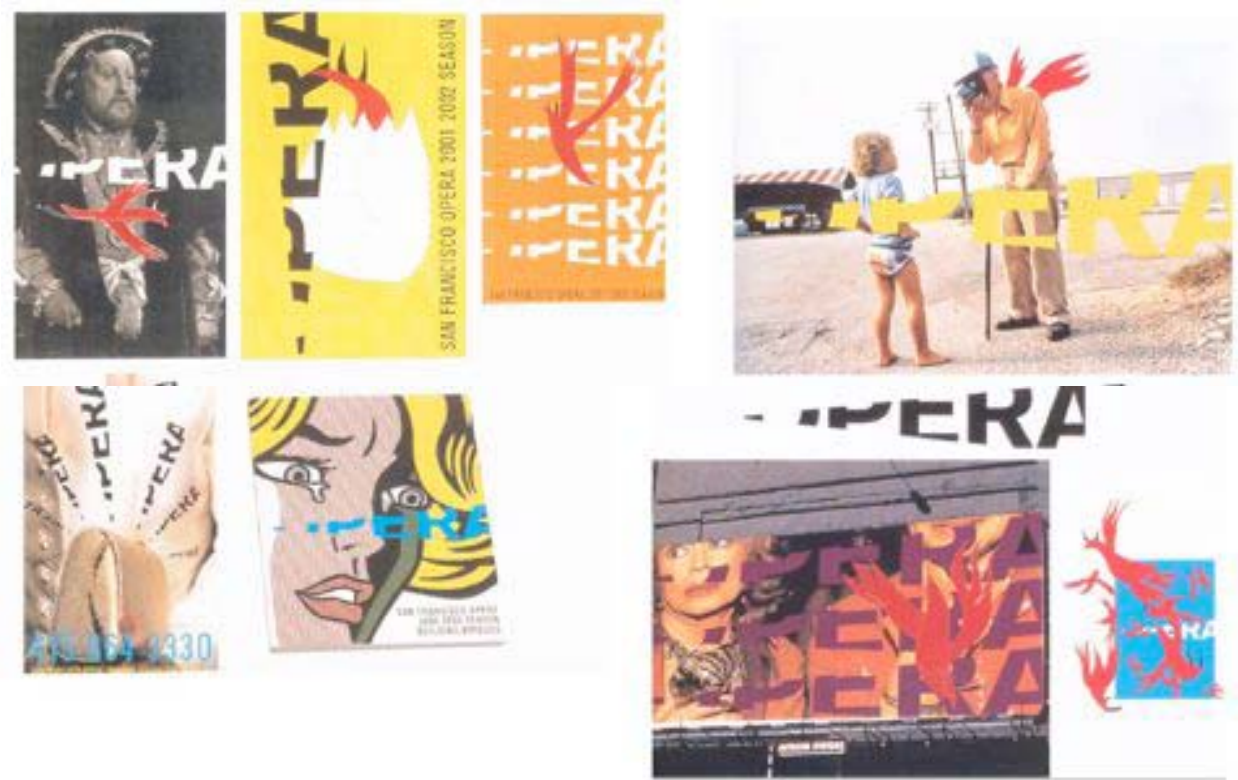

Gambar 10 Closure:

Otak kita secara otomatis mengubungkan apa yang kurang, tidak lengkap
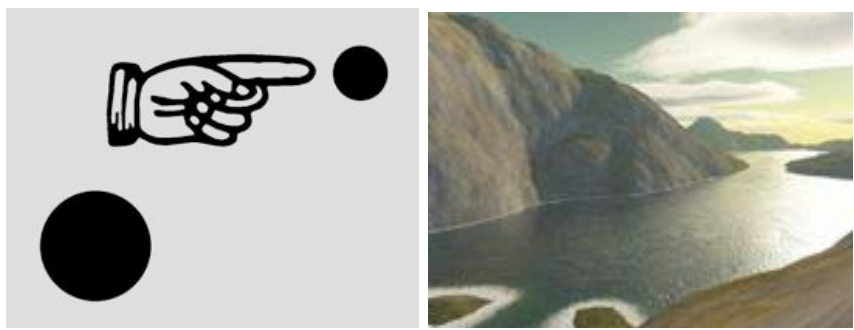

Gambar 11 Continuance:

Adanya kesinambungan menunjukkan arah, posisi

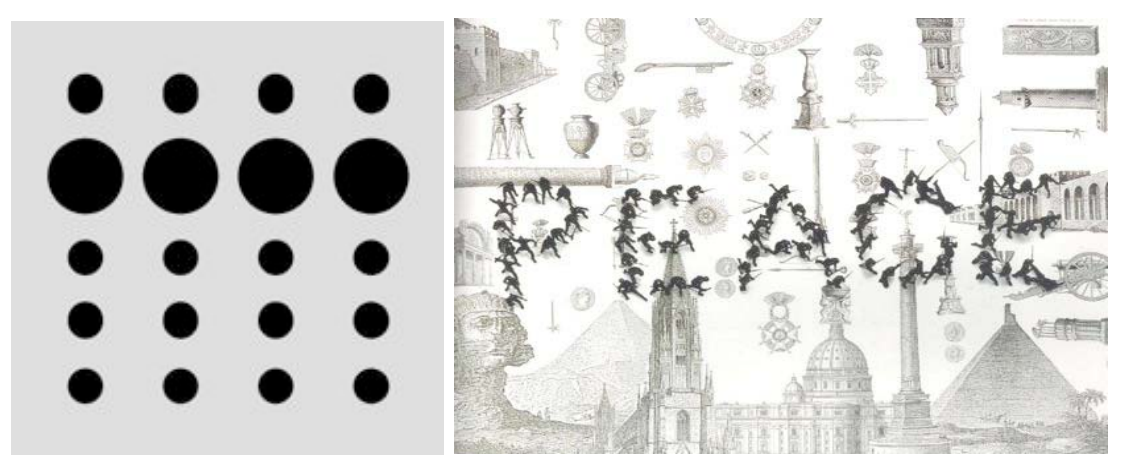

Gambar 12 Similarity:

Adanya kesamaan diantara bentuk, ukuran dan warna 


\section{$\begin{array}{ll}\because \text { FREE } & \text { WATER } \\ \text { FOOD } & \text { SOLD }\end{array}$}

Gambar 13 Proximity:

Adanya kedekatan diantara elemen yang hadir

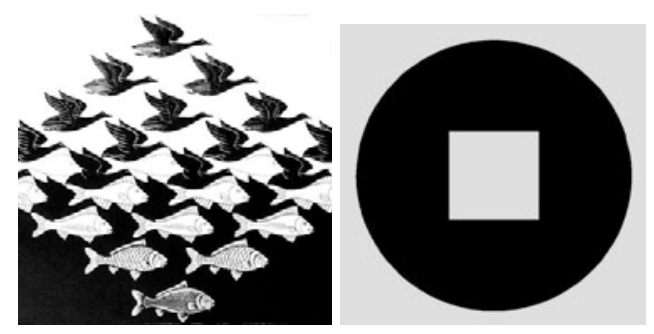

Gambar 14 Figure and ground:

Ada background, ada foreground, positif-negatf

Constuctivism / prinsip konstuksi, dengan membangun dan menata elemen-elemen desain dalam hal ini huruf, membentuk suatu konstuksi ideal, menggunakan prinsip komposisi/ desain, yaitu: Rhythm, Depth, Unity, dan Balance, ditambah satu clue/trik visual yaitu Emphasis, dengan tujuan menghasilkan visual yang memiliki sopping power.

\section{Pembahasan:}

\section{One Village Coffee}

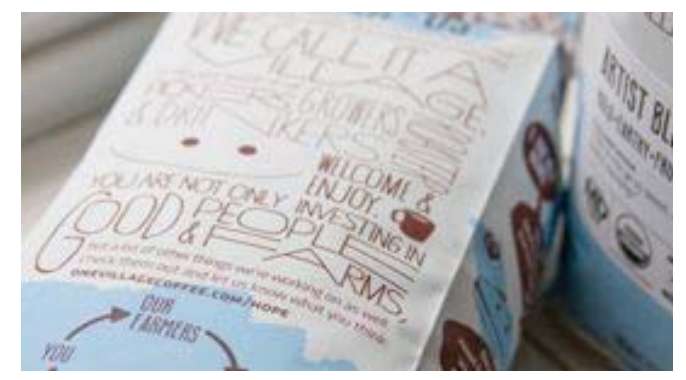

Gambar 16 Kemasan One Village Coffee (Able, ND)

Komposisi huruf yang menarik, bermain, dinamis, sudah pasti mengadopsi pprisip desain Rhythm, dengan bermain huruf besar kecil, dengan tetap menjaga Unity, karena menggunakan jenis huruf yang sama dan garis ketebalan yang sama pula, Dept, sungguh terasa disebabkan adanya besar kecil huruf dengan permainan ruang, sehingga terasa kedalamannya walau dua dimensi, prinsip Gestalt similarity pun di adopsi adanya kesamaan garis dan bentuk sehingga arah baca dipandu karena adanya pengelompokan yang sama, begitu pula kesamaan dalam kelompok warna. Tampilan tipografi yang cantik menambah semangat informasi yang disampaikan, sehingga keseluruhan komunikasi tercapai dengan persuasive Produk kopi yang bersih, hiegienis, dengan pengolahan yang baik. Dari ladang sendiri. 


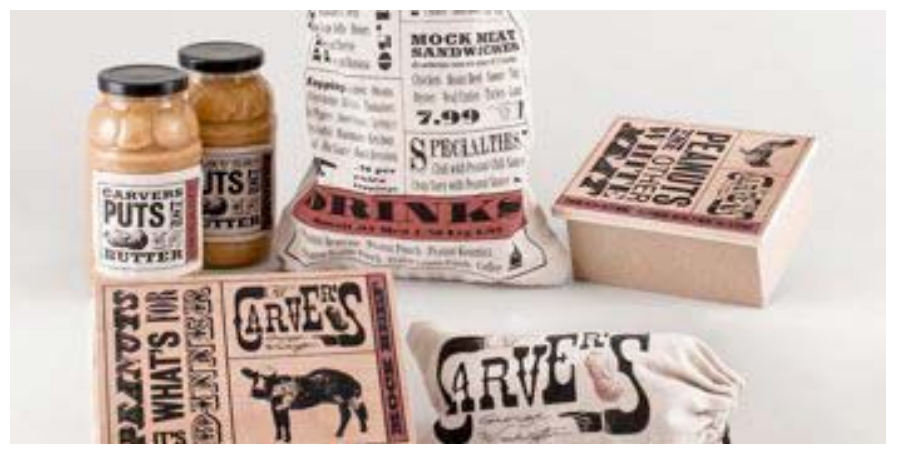

Gambar 17 Carvers Restaurant (Schwarts, ND)

Keberanian dalam mengelola jenis huruf yang berbeda, patut diberikan dua jempol, sebagai apresiasi terhadap eksperimen penyatuan beda karakter yang kuat dalam satu bidang/space. Desain ini menjadi unik, sungguh memiliki kekuatan sendiri dan memunculkan daya pikat kuat karena diferensiasinya. Persepsi yang dinyatakan jelas perbedaan jenis huruf, jelas pengelompokannya.

Dengan perbedaan itu penataannya cukup sederhana, tidak terlalu ekstrim dengan perbedaan ukuran dalam satu ruang. Garis pemisah pada kemasan karung dibelakang, komposisinya jadi dinamis, karena ada bobot dari beberapa kelompok huruf yang menghasilkan Depth/kedalaman, ada tone disana, pada botol dua di kiri, hirarkhinya jelas apa yang mau pertama dikomunikasikan. Bermegah dengan huruf(form driven), juga komposisi ideal dari golden section sangat kental pada desain ini.

\section{Christine Cushing's}

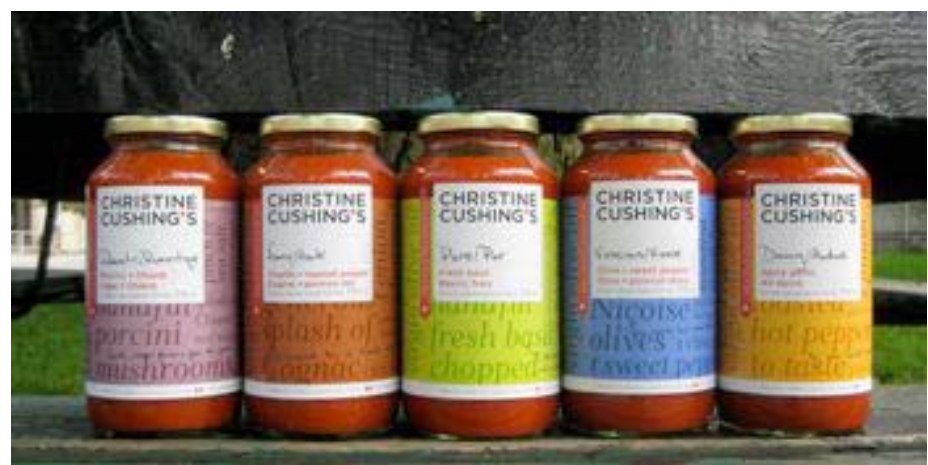

Gambar 18 Desain kemasan Christine Cushing’s (Papadakos, 2008)

Komposisi huruf pada Lebel design makanan ini memiliki kecerdikan dalam membagi ruang informasi, jelas terlihat hirarkhi bacanya, walau tampak ada figure and ground disana, bidang putih dengan dua jenis karakter huruf , satu script yang lain sanserif / tanpa kait hingga keserasian dua karakter itu melebur menjadi satu kesatuan makna, background yang berwarna dengan huruf yang senada, terasa memunculkan bidang putih kedepan, kedalaman dari komposisi ini sangat terasa, bidang putih diisi huruf keterangan produksen menjadi baseline dari komunikasi keseluruhan. Yang menarik emphasis banner merah dengan teks putih(reverse) berfungsi sebagai splash, memberikan nilai tambah dari keindahan komposisi berbagai huruf yang di diikat dalam frame-frame : putih, merah dan waran-warni sesuai background varian produknya. Untuk dicatat juga, jarak antar baris background huruf warna-warni pas banget, tidak terlau dekat, tidak juga terlalu jauh (minimal-baseline grid). Kesan elegan menghiasi komposisi bersih serta simple. 


\section{Soso Factory}

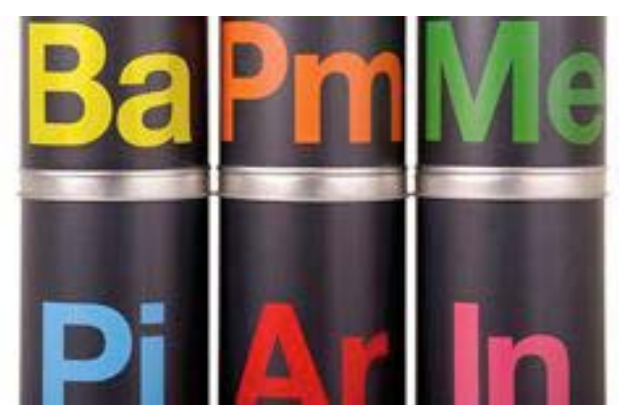

Gambar 19 Desain Soso Factory (del Fraile, ND)

Jika tiga diatas, bermain dalam banyak jenis huruf, desain yang satu ini sangat simple, minimalis, fungsional, setiap elemen yang hadir. Abstraksi huruf yang terpenggal memberikan makna yang kuat akan karakter produk didalamnya. Jenis huruf yang digunakanpun sesuai konsep positioning produknya, Persepsi awal sudah sangat terasa kuat, sama jenis dan besar huruf yang di bawah dengan yang di atas, kerning huruf yang tepat tidak menempel namun masih ada ruang yang melahirkan negatif space, tetapi dipisahkan dalam warna, disinilah bermain sekaligus memberi focal point, point of interest. Pada desain ini huruf benar-benar menjadi image/gambar/visual. Dengan eksekusi cetak dan finishing yang yang cerdas, background doff dan huruf glossy, warna-warna primer lebih 'muncul'.

\section{Ashley Lewis}

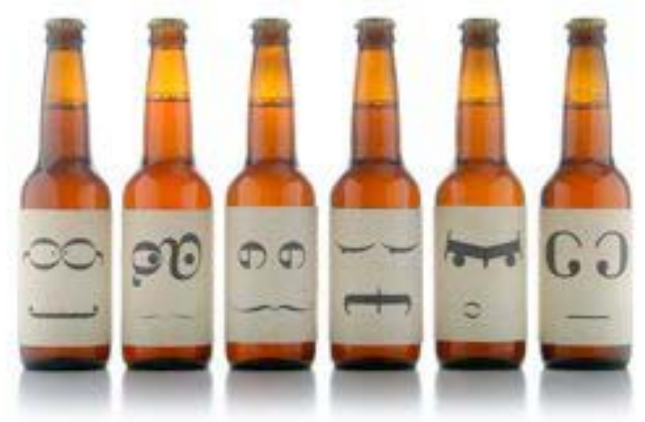

Gambar 20 Desain Ashley Lewis (Lewis, ND)

Jika ditengok kembali referensi diatas tentang definisi dari Typeface (adalah kumpulan karakter, huruf, nomor, symbol, dan tanda baca yang memiliki kesamaan desain) maka akan ada jawaban, yaa.., ini juga huruf, walau dirancang sedemikian rupa bisa membentuk gambar tertentu yang memiliki arti denotative, tetapi dengan jelas ini terlihat sebuat komposisi huruf, yang bermain dengan position, tiap-tiap huruf yang mewakilkan ekspresi/gentur orang tentunya mengambil perhatian audiece, jadi emphasisnya sangat kuat. Minimalis, berkarakter, diferensiatif, unik. Prinsip unity termuat denagn baik, terasa sintaktik, menggunakan typeface yang sama(jenis huruf yang sama). Gestalt teory benar-benar diadopsi sepenuhnya, memperhatikan mata yang dinamis, menuju kearah yang berlainan, itu diarahkan oleh prinsip Continuance. Selaras dengan tujuan desai ini menghantar minum bersama. 


\section{SIMPULAN}

Banyak hal yang bisa ditarik simpulan dari referensi dan pembahasan tipografi, yaitu: Pertama, Huruf memilki sangat kuat karakter, sehingga didapati anatomi huruf yang sangt kompleks; kedua, huruf adalah elemen esensi dari desain, tak bisa dielakkan kehadirannya, dan musti dikelola dengan baik agar bisa berkomunikasi maksimal; ketiga, huruf sejatinya tampil sebagai visual agar bisa lebih banyak memberikan makna. Kemudian ada tiga lagi kriteria komposisi visual (form), yaitu: (1) Unik, karena begitu dibombardirnya dimana-mana akan visual, maka otak tidak mampu menerima sesuatu yang sama dan sulit dibedakan, maka dia harus ada nilai pembeda, entah itu kebaharuan, pengolahan visual yang berlebih, atau ada nilai tambah create value); (2) Simpel, lagi-lagi otak tidak mau menerima yang rumit, sulit dimengerti, membutuhkan waktu untuk mencerna, otak ingin menerima informasi yang sederhan, makin sederhana semakin mudah diserap. Metafora, unik dan simple, berterima saja tidak cukup, visual perlu berceritera (visual language), dengan adanya ceritera maka memori yang melekat jauh lebih lama, diharapkan permanen.

\section{DAFTAR PUSTAKA}

Able (ND). One Village Coffee. Diunduh dari http://designedbyable.com/ovc.php

Ambrose, G., Harris, P. (2006). The Fundamentals of Typography. AVA Publishing SA.

Capsule, (2007), Design Matters: Logos - An Essential Primer for Today’s Competitive Market: v. 1., USA: Rocport Publishers, Inc.

Del Fraile, J. (ND). Soso Factory. Diunduh dari http://www.thedieline.com/blog/2010/8/17/sosofactory.html

Felici, J. (2002). The Complete Manual of Typography. USA: Adobe Press.

Fishel, C. (2003). Design secrets: Packaging: 50 Real-Life Projects Uncovered, USA: Rockport Publishers, Inc.

Franzia, E. (2009). Karakter kartun pada kemasan makanan ringan. Jurnal Dimensi Vol 6 No 2 Februari 2009.

Lester, P. M. (2003). Visual Communication: Images with Messages. USA: Thomson Wadsworth.

Lewis, A. (ND) Ashley Lewis Portfolio. Diunduh dari http://www.thedieline.com/blog/2010/4/21/student-spotlight-ashley-lewis.html

Papadakos, T. (2008). Christine Cushing*s packaging. Diunduh dari http://www.behance.net/gallery/Christine-Cushings-packaging/103617

Samara, T. (2007). Design Elements: A Graphic Style Manual, USA: Rocport Publishers, Inc.

Schwartz, J. C. (ND), Carver's Restaurant. Student Portfolio. Diunduh dari http://www.coroflot.com/drummerguy47/CaversRestaurant 